\title{
Egressos das licenciaturas: o que move a escolha e o exercício da docência ${ }^{1}$
}

\section{Teaching degree graduates: What motivates the choice to the degree and working as a teacher}

\author{
Vera Lucia Felicetti*
}

\begin{abstract}
RESUMO
Ao professor em sala de aula se exigem e se atribuem responsabilidades para além da docência. A ele cabe frequentemente resolver problemas familiares e sociais que os alunos trazem para o contexto escolar, e a ele não é dada a valorização social e econômica que tem direito. Diante de tais pressupostos, este artigo apresenta um estudo com egressos bolsistas ProUni e não bolsistas dos cursos de licenciatura de uma Instituição de Ensino (IES) comunitária do Rio Grande do Sul e objetivou responder aos questionamentos: O que leva as pessoas a optarem pelos cursos de licenciatura ao ingressarem na universidade? O quanto estão satisfeitos ou insatisfeitos com a formação conquistada? O quanto estão satisfeitos ou insatisfeitos com o exercício da docência? O cunho metodológico usado foi o quantitativo e dos 60 egressos convidados a responderem ao questionário, houve 52 respondentes. As análises indicam que aspectos relacionados às características iniciais dos candidatos à docência, tais como afinidades, habilidades, perspectivas sociais, entre outros, têm associação com a escolha do curso e a satisfação com a graduação. Os dados também indicam que tanto os egressos que foram bolsistas ProUni como os que não foram bolsistas têm características e percepções semelhantes acerca do curso escolhido.
\end{abstract}

Palavras-chave: Cursos de licenciatura. Egressos. Escolha docente.

1 Projeto de investigação com financiamento da Fundação de Amparo à Pesquisa do Rio Grande do Sul - FAPERGS.

* Universidade La Salle. Canoas, Rio Grande do Sul, Brasil. E-mail: vera.felicetti@unilasalle. edu.br. http://orcid.org/0000-0001-6156-7121 


\begin{abstract}
Responsibilities that go beyond teaching are required of and attributed to teachers in the classroom. It is up to them to solve family and social problems that the students bring to the school context, and they do not receive the social and economic appreciation that they deserve. Faced with these assumptions, this article presents a study with graduates; with or without ProUni grants from the teaching degree programs of a nonprofit Education Institution from Rio Grande do Sul and aims to answer the following questions: what leads people to choose teaching degree programs upon entering university? How satisfied or dissatisfied are they with the education they obtained? How satisfied or dissatisfied are they with the teaching practice? The methodological framework used was quantitative and of the 60 graduates invited to answer a questionnaire, 52 responded. The analyses indicate that aspects related to the prior characteristics of the teaching candidates, such as compatibilities, skills, social perspectives, among others, were associated to the choice of the program and to satisfaction with the undergraduate degree. The data also indicate that the ProUni grant holders as well as those who did not have grants had similar characteristics and perceptions regarding the program chosen.
\end{abstract}

Keywords: Teaching degree programs. Graduates. Teaching choice.

\title{
Introdução e aporte teórico
}

O Art. 205 da Constituição Federal Brasileira de 1988 determina a educação como direito de todos e dever do Estado e da família, sendo esse direito garantido pela Lei de Diretrizes e Bases (LDB), sendo o Plano Nacional de Educação (PNE) o responsável pela sua implementação. O PNE, Lei nº . 13.005, de 25 de junho de 2014 - decênio 2014-2024 apresenta entre suas premissas a universalização da educação básica; anteriormente, o PNE decênio 2001-2010 implementou a universalização do Ensino Fundamental. Essa universalização, ou seja, uma escola para todos, desencadeou mudanças no perfil escolar, pois a partir dela não só houve aumento do número de alunos, como também foi possível o acesso de diferentes perfis estudantis ao contexto educacional.

Ter uma escola para todos no discurso é muito diferente de se ter uma escola para todos na prática. "Pois uma coisa é ter uma escola para públicos já predispostos à escolarização e na qual ficam aqueles que se adaptam aos seus rituais e sobrevivem às suas exigências", e outra é ter uma "prática cotidiana que não apenas dê conta do jogo das diferenças, mas que assegure aos desiguais 
às mesmas condições de percurso" (ARANHA; SOUZA, 2013, p. 77). No jogo das diferenças, segundo esses autores, não se encontram somente alunos provenientes de lugares diferentes, mas também, alunos desiguais. Associada à universalização e ao jogo das diferenças, nela inserido, está a necessidade, não somente do aumento de profissionais da educação, a fim de atenderem as demandas em questão, mas também de profissionais capazes de lidarem com tamanha diversidade no contexto escolar.

Diante do exposto, ao professor, parece atribuírem-se responsabilidades para além de sua função primordial de ensinar. A ele cabe dar atenção e, por que não dizer, resolver os problemas sociais e familiares que os alunos trazem para dentro da sala de aula, relacionar-se e atuar com e na comunidade onde exerce a docência, além de ter um perfil gestor entre outras responsabilidades (NÓVOA, 2009). Isso significa, segundo Nóvoa" (2004, p. 9), que "ao professor pede-se tudo". No entanto, mesmo com todas essas funções agregadas, o professor tem sido cada vez menos prestigiado do ponto de vista social (ARANHA; SOUZA, 2013). Isso expressa uma contradição: se por um lado se expande o acesso ao ensino, demanda-se automaticamente maior quantidade de profissionais e melhor qualificados, porém, por outro lado, apresenta-se a dificuldade de formar professores para atender tal demanda, em virtude da desvalorização dada à profissão.

A desvalorização da profissão docente, a baixa remuneração, o excesso de atribuições e cobranças têm afastado os professores da docência, bem como inibido novos candidatos a ingressarem na profissão ou optarem por cursos de licenciatura quando do ingresso na universidade (ARANHA; SOUZA, 2013).

A fim de melhorar a valorização da profissão docente, a mesma constitui-se em um dos principais pontos do Plano de Desenvolvimento da Educação (PDE) que tem entre suas metas a de número 17 que objetiva "valorizar os(as) profissionais do magistério das redes públicas de educação básica de forma a equiparar seu rendimento médio ao dos(as) demais profissionais com escolaridade equivalente, até o final do sexto ano de vigência deste PNE" (BRASIL, 2014).

Ao encontro dessa Meta, Sahlberg (2011) aponta que os professores, tal como médicos ou economistas, são profissionais de alto nível e necessitam ter um salário equiparado ao de outras profissões com mesma formação. Também argumenta o autor que os professores necessitam de uma formação teórica sólida, bem como de uma formação prática. Ainda para ele, a existência de um plano de carreira com perspectivas de desenvolvimento e crescimento são importantes à docência.

Isso se justifica, pois, associada à melhoria da qualidade da educação básica está, a formação de seus professores, bem como as oportunidades a eles oferecidas. Em extensão, a qualidade da educação superior e a formação dada aos seus graduados estão associadas à formação dos egressos oriundos da 
educação básica, estabelecendo-se assim, entre o Ensino Superior e a educação básica, um ciclo evidente e contínuo de dependência.

Nessa direção, a profissão docente exige atenção em todos seus estágios de desenvolvimento, ou seja, na entrada e no percurso na universidade, e quando da entrada na profissão e no contínuo da mesma. Quando da entrada na universidade, há a necessidade de atenção aos aspectos relacionados ao perfil do candidato à docência, pois, "quando ingressam no curso de formação inicial, os futuros professores trazem consigo uma história de vida que pode ter influenciado e condicionado, por vezes de forma decisiva, a estruturação de algumas das características de personalidade" (SECO, 2005, p. 83). Seco afirma que, durante o processo de formação inicial, há a necessidade de transformações em curso, ou seja, de melhorar a qualidade dos recursos humanos, sem descuidar da valorização e dignificação do papel docente a fim de estruturar-se um conjunto de condições capazes de proporcionar a satisfação no exercício da docência.

Durante a formação inicial, consolida-se ou não a escolha pelo curso devido aos aspectos inerentes a ele desenvolvidos. Sendo assim, a "evidência é clara... que as diferentes experiências nas diversas áreas do conhecimento têm impactos além daqueles atribuíveis à seleção inicial para essas áreas." (FELDMAN; NEWCOMB, 1969, p.193, reticências do original. Em síntese, a seleção inicial e os efeitos subsequentes ao contínuo acadêmico estão relacionados com a escolha da área de estudo.

Junto à escolha e à formação da docência, desenvolvida no curso, está a satisfação e a realização docente que, segundo Seco (2005, p. 88), está associada "à influência de algumas dimensões da sua personalidade na experienciação de um maior ajustamento a uma actividade que consideramos desafiante, diversificada e potencialmente inovadora.".

Acerca da personalidade, Walsh e Holland (1992) apontam que uma enorme quantidade de pesquisas sinaliza que os estudantes universitários tendem a selecionar e entrar em áreas e ambientes congruentes com seus tipos de personalidade. Para os autores, a satisfação e o sucesso, ou a realização no ambiente educacional ou de trabalho depende da congruência entre o tipo de personalidade e o ambiente.

A revisão da literatura realizada por Borchert (2002), acerca dos intervenientes à escolha da profissão, aponta três fatores como principais: o ambiente, a oportunidade e a personalidade. Segundo o autor, os fatores de personalidade a serem considerados incluem as capacidades mentais, habilidades especiais e interesses. Nessa direção, "Algumas carreiras exigem que você tenha a personalidade correspondente às qualidades da ocupação" (BORCHERT, 2002, p. 12). $\mathrm{O}$ ambiente familiar, a comunidade na qual estão inseridos, as experiências escolares anteriores, as aptidões, as habilidades e os interesses pessoais também 
podem influenciar na escolha, assim como nas oportunidades (BORCHERT, 2002; GRAMANI, SCRICH, 2012).

Para Splaver (1977) é importante que o aluno tenha uma boa compreensão de si, de sua personalidade para fazer a escolha certa da profissão. A personalidade pode envolver as atitudes e opiniões que influenciam a forma como as pessoas interagem umas com as outras e, em particular, como lidam com as situações de escolha da profissão (BORCHERT, 2002).

Estudos de Feldman e Newcomb (1969) evidenciam a congruência entre a área escolhida e a personalidade dos acadêmicos. Segundo eles, os alunos das engenharias e ciências naturais têm altos escores em valores teóricos, estudantes de gestão têm altos escores em valores políticos, estudantes de administração têm altos escores em valores econômicos e estudantes da área de educação e ciências sociais têm altos escores em valores sociais.

Os valores sociais têm alta relevância entre os estudantes da área de educação, isso evidencia a íntima relação entre a personalidade, a escolha e as afinidades com a profissão. Contudo, é no processo de formação docente que são fortalecidas as escolhas e as intenções para com a profissão. Sendo assim, o magistério está associado à identidade docente e à singularidade da função social que necessita exercer, sendo confundido o progresso coletivo com o projeto e as ambições individuais dos professores, bem como com a finalidade de ensino que lhe compete.

Para Valle (2006), a dinâmica que orienta a escolha pelo magistério repousa sobre lógicas relacionadas à representação que eles têm de si, ao ingresso no mundo do trabalho e da função social que evidenciam ter. A escolha pela profissão professor, segundo a autora, constitui-se fruto da doação e da vocação, relacionadas a ligações afetivas tanto na relação pedagógica (professor/aluno) como na institucional (professor/direção/colegas), mas decorre também das representações associadas à profissão. Sendo assim:

Escolher a docência é, portanto, atribuir-lhe um sentido, situando-a em relação à sua vida e às suas aspirações profissionais; é inserir-se num espaço social bem preciso e num sistema de relações interpessoais claramente definidas, com o objetivo de reafirmar a estima de si. (VALLE, 2005, p. 184).

O desejo de ser professor constitui-se a principal razão para a escolha dos cursos de licenciatura, segundo estudos realizados por Brito (2007) ao analisar as respostas dadas por estudantes dos cursos de Licenciatura ao Exame Nacional 
de Desempenho dos Estudantes ${ }^{2}$ (ENADE) de 2005 juntamente com análise dos dados do Censo da Educação Superior. Isso evidencia a importância de pensar na escolha educacional e profissional dos indivíduos e na importância de tais escolhas para a estabilidade educacional e vocacional, para a satisfação e o sucesso no exercício da formação e da profissão (SMART; FELDMAN; ETHINGTON, 2000). Rabelo (2010) escreve que a importância da docência está no gostar do que se faz, pois somente assim é possível encontrar forças para lutar por melhor formação e atuação.

Desse modo, pode-se pensar que a escolha pelo magistério pode estar associada à identidade docente e à singularidade de sua função, pois mesmo com um cenário desestimulador dado à profissão docente no Brasil, ainda tem-se, embora em quantidade insuficiente à demanda exigida, ingressantes e egressos nos e dos cursos de licenciatura, bem como novos professores se inserindo na carreira docente.

Diante dos desafios que permeiam a profissão docente, questiona-se: $\mathrm{O}$ que leva as pessoas a optarem pelos cursos de licenciatura ao ingressarem na universidade? O quanto estão satisfeitos ou insatisfeitos com a formação conquistada? O quanto estão satisfeitos ou insatisfeitos com o exercício da docência?

No intuito de tentar responder a tais questionamentos, este artigo apresenta um estudo realizado com egressos dos cursos de licenciatura ${ }^{3}$ de uma instituição comunitária da Grande Porto Alegre no Estado do Rio Grande do Sul. Assim, na sequência apresenta-se a metodologia usada na investigação, a análise e a discussão dos dados entrelaçadas a teóricos pertinentes, a conclusão e as referências.

\section{Metodologia}

A abordagem metodológica usada nesta investigação teve cunho quantitativo com objetivo explicativo. Segundo Booth, Colomb e Williams (2000), a abordagem quantitativa possibilita determinar o perfil do grupo em estudo, bem como medir tanto opiniões quanto atitudes, preferências e comportamentos dos envolvidos na investigação. $\mathrm{O}$ objetivo explicativo preocupa-se não somente em identificar os fenômenos, mas também as suas causas aprofundando o conhecimento da realidade.

2 Exame Nacional de Desempenho dos Estudantes (ENADE) é composto da prova, do questionário de avaliação da prova, do questionário dos coordenadores e do questionário socioeconômico.

3 Ciências Biológicas, Computação, Educação Física, Filosofia, Física, Geografia, História, Letras, Matemática, Pedagogia, Química. 
Primeiramente foram coletados junto ao protocolo da Instituição de Ensino Superior em foco os dados gerais acerca dos ingressantes na instituição nos cursos de licenciatura (Ciências Biológicas, Computação, Educação Física, Filosofia, Física, Geografia, História, Letras, Matemática, Pedagogia, Química). nos anos de 2007, 2008 e 2009, totalizando 1.254 estudantes. Na sequência, os dados foram organizados na planilha Excel e após importados pelo EPI-INFO versão 7.1. Essa organização possibilitou identificar os alunos já graduados até o segundo semestre de 2012, os quais corresponderam a 60 egressos. Estes foram também classificados em dois grupos, os que tiveram bolsa ProUni e os que não tiveram esse auxílio.

Com a situação dos alunos identificada, foi possível enviar o instrumento de pesquisa aos 60 egressos, dos quais 44 (73,3\%) não tiveram bolsa ProUni e $16(26,7 \%)$ foram bolsistas. O questionário foi reorganizado e apoiado no instrumento já aplicado por Felicetti (2011a). O mesmo foi editado no Google Docs onde foi criado um link e codificado para cada um dos 60 egressos. Enviou-se um e-mail, no segundo semestre de 2012, a cada um dos egressos, convidando-os a participarem da pesquisa, informando o objetivo da mesma e o respectivo link de acesso ao questionário. Retornaram, após quase seis meses de envios e reenvios, 52 questionários respondidos, correspondendo a $86,7 \%$ dos convidados a participarem, satisfazendo os parâmetros utilizados para o cálculo amostral que foi baseado em 95\% e assumiu-se um erro amostral tolerável de 5\%.

Como o estudo comparou dois grupos, em questão egressos ProUni e egressos não ProUni dos cursos de licenciatura ingressantes na IES em foco em 2007, 2008 e 2009, a amostra estratificada desejável corresponde a 13,9 Prounistas e 38,3 não Prounistas, isto é, 14 e 38 egressos respectivamente. A amostra estratificada também foi satisfeita.

A organização dos dados foi feita no Excel, após isso os dados foram importados pelo EPI-INFO versão 7.1, através do qual se realizaram análises estatísticas pertinentes a este estudo. Ainda no Excel, foram atribuídos valores de acordo com os formatos de respostas na Escala Likert. Foram usados dois formatos. No primeiro formato da escala, a atribuição ficou assim: discordo totalmente foi substituída por 1; discordo parcialmente por 2; a não concordo nem discordo por 3; concordo parcialmente por 4 e concordo totalmente por 5 . No segundo formato de escala, a atribuição ficou assim: totalmente insatisfeito foi substituído por 1; parcialmente insatisfeito por 2; nem satisfeito nem insatisfeito por 3; parcialmente satisfeito por 4 e totalmente satisfeito por 5. Essas atribuições foram necessárias para poder calcular a média e desvio-padrão. Assim, considerou-se a média máxima de 5 em cada grupo analisado.

As respostas oriundas dos itens referentes à questão que abordava as razões que levaram os egressos a escolherem o curso de formação, foram organizadas 
em cinco grupos: afinidades e habilidades; desafios; tempo; acesso; e, por fim, os aspectos sociais denotados à profissão.

As questões voltadas às dificuldades enfrentadas pelos egressos durante o percurso acadêmico foram distribuídas em três grupos, a saber: dificuldades materiais, dificuldades inter-relacionais e dificuldades de pré-requisitos.

Quanto às respostas das questões relacionadas à satisfação, elas foram agrupadas em quatro grupos: grupo satisfação pessoal; satisfação social; satisfação com a oferta de trabalho na sua área de formação; satisfação institucional e satisfação com os professores.

Quanto à questão referente à possibilidade de fazer o mesmo curso se pudessem começar novamente, as opções de resposta foram: definitivamente sim; provavelmente sim; sem opinião formada; provavelmente não e definitivamente não, para as quais foi usada a frequência e seu respectivo percentual. A mesma frequência foi usada na questão referente ao fazer curso após a graduação.

Tabelas de distribuição foram construídas para os grupos ProUni e não ProUni. O Qui-quadrado foi calculado para testar a associação entre ser ou não prounista, o sexo, a faixa etária do aluno e a raça. O teste t de Student foi usado para observar se houve diferença significativa entre as médias das notas e dos escores entre os dois grupos de alunos. Níveis de significância $<5 \%(\mathrm{p}<0,05)$ foram considerados significativos e entre 5 e $10 \%(0,05$ e 0,1$)$ considerados como indicativos de significância (BÓS, 2004).

\section{Análise e discussão dos dados}

Informações acerca do sexo, da idade e da raça são apresentadas na Tabela 1. Quanto ao sexo, tanto no universo não ProUni como no ProUni, o maior percentual corresponde ao das mulheres: $60,5 \%$ (23) e 57,1\% (8) respectivamente, correspondendo a 59,6\% (31) dos 52 respondentes. Para a faixa etária foram considerados os com menos de 18 até 24 anos e os com mais de 24 anos quando do ingresso na universidade, sendo que entre os não ProUni 71,0\% (27) tinham menos de 18 até 24 anos, e entre os ProUni 50\% (7) estavam nessa mesma faixa etária, totalizando o percentual de $65,4 \%$ (34). A raça com maior percentual apresentado foi a branca, sendo 89,5\% (34) entre os não ProUni e 92,9\% (13) entre os prounistas, representando $90,4 \%$ (47) do total de respondentes. 
TABELA 1 - SEXO, FAIXA ETÁRIA E RAÇA DOS EGRESSOS RESPONDENTES ProUni E NÃO ProUni

\begin{tabular}{|c|c|c|c|c|}
\hline \multicolumn{2}{|c|}{ Fr. $(\%)$} & $\begin{array}{c}\text { Não ProUni } \\
\text { Fr. (\%) }\end{array}$ & $\begin{array}{l}\text { ProUni } \\
\text { Fr. (\%) }\end{array}$ & TOTAL \\
\hline \multirow{2}{*}{ SEXO* } & Feminino & $23(60,5)$ & $8(57,1)$ & $31(59,6)$ \\
\hline & Masculino & $15(39,5)$ & $6(42,9)$ & $21(40,4)$ \\
\hline \multirow[t]{2}{*}{ FAIXA ETÁRIA* } & $\begin{array}{c}\text { Menos de } 18 \text { a } \\
24 \text { anos }\end{array}$ & $27(71,0)$ & $7(50)$ & $34(65,4 \%)$ \\
\hline & Mais de 24 anos & $11(29,0)$ & $7(50)$ & $18(34,6 \%)$ \\
\hline \multirow{3}{*}{ RAÇA* } & Parda & $3(7,9)$ & $1(7,1)$ & $4(7,7)$ \\
\hline & Preta & $1(2,6)$ & 0 & $1(1,9)$ \\
\hline & Branca & $34(89,5)$ & $13(92,9)$ & $47(90,4)$ \\
\hline \multicolumn{2}{|c|}{ TOTAL } & $38(100)$ & $14(100)$ & $52(100)$ \\
\hline
\end{tabular}

FONTE - Banco de dados formado pelas respostas dos questionários.

* Qui quadrado não significativo.

A análise das respostas das questões referentes aos aspectos que levaram os egressos a escolherem o curso no qual se graduaram, Tabela 2 , evidencia que o grupo afinidade/habilidade, tanto para os egressos que foram prounistas como para os não prounistas teve a maior média, correspondendo esta respectivamente a 4,7 e 4,5, em extensão o menor desvio-padrão, caracterizando que as respostas tendem a estar próximas da média. A segunda maior média, para ambos os egressos está no grupo desafios com 4,3 para os não ProUni e 4,6 para os que foram prounistas. A terceira está no grupo aspectos sociais, com 3,1 para os que não foram bolsistas e 3,4 para os que foram. Na sequência, o grupo tempo para conclusão do curso com 2,6 de média em ambos egressos. Por fim, o grupo acesso ao curso com 2,1 para os não bolsistas e 2,0 para os que foram bolsistas. Não houve significância estatística entre os dois grupos, ProUni e não ProUni.

TABELA 2 - ASPECTOS QUE LEVARAM À ESCOLHA DO CURSO

\begin{tabular}{ccccc}
\hline GRUPOS & $\begin{array}{c}\text { Não ProUni } \\
\text { Média } \pm \text { d.p }\end{array}$ & $\begin{array}{c}\text { ProUni } \\
\text { Média } \pm \text { d.p }\end{array}$ & P & $\begin{array}{c}\text { TOTAL } \\
\text { Média } \pm \text { d.p }\end{array}$ \\
\hline 1. AFINIDADE/HABILIDADE & $4,5 \pm 0,57$ & $4,7 \pm 0,47$ & 0,31 & $4,6 \pm 0,54$ \\
2. DESAFIOS & $4,3 \pm 0,60$ & $4,6 \pm 0,60$ & 0,24 & $4,4 \pm 0,60$ \\
3. TEMPO & $2,6 \pm 0,91$ & $2,6 \pm 1,26$ & 0,88 & $2,6 \pm 1,0$ \\
4. ACESSO & $2,1 \pm 0,93$ & $2,0 \pm 1,02$ & 0,56 & $2,1 \pm 0,95$ \\
5. SOCIAL & $3,1 \pm 0,86$ & $3,4 \pm 0,79$ & 0,34 & $3,2 \pm 0,85$ \\
\hline
\end{tabular}

FONTE: Banco de dados formado pelas respostas dos questionários. 
As médias apresentadas na Tabela 2, tanto por parte dos prounistas como dos não prounistas, apontam com maior média, a escolha relacionada a aspectos tais como afinidades, habilidades, o enfrentamento de desafios e interesses sociais voltados à profissão. Esses aspectos evidenciam ainda, embora em menor média, que a escolha pelo curso perpassa pelo fato de serem cursos com pouca procura ao acesso, o que resulta em uma menor concorrência para o ingresso ou então por ser um curso de menor custo financeiro ou com um tempo de conclusão menor que muitos outros cursos de não licenciatura. Tais resultados indicam que a profissão docente é uma escolha associada a diferentes fatores (ALMEIDA, 1998; FERNANDES, 2004), entre eles as percepções de seus próprios interesses e habilidades (SMART; FELDMAN; ETHINGTON, 2000; SPLAVER, 1977; BORCHERT, 2002). A média, aqui encontrada, associada aos fatores sociais, vai ao encontro dos estudos de Feldman e Newcomb (1969) que apontam que alunos da área da educação têm forte relação com valores sociais.

As dificuldades apresentadas pelos egressos foram organizadas em três grupos, e os percentuais correspondentes a cada grupo constam na Tabela 3. Nela pode ser observado, que a maior média apresentada entre os egressos correspondeu às dificuldades materiais enfrentadas por eles com a média de 2,95 , tendo os egressos ProUni a maior média a qual foi de 3,13 . Já entre os não prounistas, a média ficou em 2,89 . O grupo das dificuldades de pré-requisitos obteve a segunda maior média geral que foi 2,48 ; para os não prounistas a média foi de 2,55 e 2,29 para os que foram bolsistas. Observa-se que os alunos que não foram bolsistas tiveram maiores dificuldades de pré-requisito na aprendizagem de novos conteúdos que seus colegas bolsistas. Já entre as dificuldades interrelacionais, os que não foram prounistas apresentaram a média maior que foi de 1,77. Alves (2008) identifica em seus estudos que os alunos participantes do ProUni não apresentam dificuldades no processo de aprendizagem, mas as dificuldades são na maioria das vezes de cunho financeiro.

TABELA 3 - DIFICULDADES APRESENTADAS PELOS EGRESSOS DURANTE O PERCURSO ACADÊMICO

\begin{tabular}{ccccc}
\hline DIFICULDADES & $\begin{array}{c}\text { Não ProUni } \\
\text { Média } \pm \text { d.p }\end{array}$ & $\begin{array}{c}\text { ProUni } \\
\text { Média } \pm \text { d.p }\end{array}$ & P & $\begin{array}{c}\text { TOTAL } \\
\text { Média } \pm \text { d.p }\end{array}$ \\
\hline 1. MATERIAIS & $2,89 \pm 1,05$ & $3,13 \pm 1,20$ & 0,49 & $2,95 \pm 1,09$ \\
2. INTER-RELACIONAIS & $1,77 \pm 0,90$ & $1,55 \pm 0,81$ & 0,42 & $1,71 \pm 0,87$ \\
3. PRÉ-REQUISITOS & $2,55 \pm 1,40$ & $2,29 \pm 1,20$ & 0,53 & $2,48 \pm 1,35$ \\
\hline
\end{tabular}

FONTE: Banco de dados formado pelas respostas dos questionários.

Pode-se inferir diante de tais dados que as dificuldades financeiras não foram apenas dos egressos que obtiveram a bolsa ProUni, mas dos demais 
também, o que evidencia que os alunos não bolsistas que frequentaram a instituição comunitária de Ensino Superior não tiveram facilidade de nela se manterem financeiramente. Não houve existência de significância estatística entre os egressos no que diz respeito às dificuldades encontradas no percurso acadêmico. Não ser uma diferença significativa representa que tal diferença pode não existir, isto é, egressos que não foram ProUni podem ter enfrentado as mesmas dificuldades que os que foram bolsistas do ProUni. O fato é que as dificuldades no percurso acadêmico existem e ingressar no Ensino Superior, via um programa de ações afirmativas, em foco aqui o ProUni, não torna os bolsistas mais ou menos privilegiados que os demais. E que tampouco os alunos não bolsistas do ProUni não têm dificuldades durante o percurso acadêmico.

$\mathrm{Na}$ Tabela 4, podem ser observadas as médias de satisfação apresentadas pelos egressos durante a graduação.

\section{TABELA 4 - MÉDIA DE SATISFAÇÃO APRESENTADA PELOS EGRESSOS}

\begin{tabular}{ccccc}
\hline SATISFAÇÃO & $\begin{array}{c}\text { Não ProUni } \\
\text { Média } \pm \text { d.p }\end{array}$ & $\begin{array}{c}\text { ProUni } \\
\text { Média } \pm \text { d.p }\end{array}$ & P & $\begin{array}{c}\text { TOTAL } \\
\text { Média } \pm \text { d.p }\end{array}$ \\
\hline 1. PESSOAL & $3,6 \pm 0,87$ & $3,5 \pm 0,90$ & 0,72 & $3,6 \pm 0,87$ \\
2. SOCIAL & $4,8 \pm 1,16$ & $4,9 \pm 1,0$ & 0,94 & $4,8 \pm 1,10$ \\
3. INSTITUCIONAL & $3,6 \pm 0,78$ & $3,9 \pm 0,95$ & 0,18 & $3,7 \pm 0,83$ \\
4. COM PROFESSORES & $4,2 \pm 0,77$ & $3,7 \pm 1,2$ & 0,10 & $4,1 \pm 0,92$ \\
\hline
\end{tabular}

FONTE: Banco de dados formado pelas respostas dos questionários.

A maior média apresentada entre os alunos que não foram bolsistas ProUni corresponde 4,8 e refere-se à satisfação social, o mesmo ocorrendo entre os que foram bolsistas com 4,9 de média. Destaca-se que a média máxima que pode ser atingida é de 5, estando assim a média da satisfação social que os egressos tiveram durante o curso, muito próxima da média máxima. A satisfação com os professores teve a média de 4,2 dos não prounistas e entre os prounistas a média para tal satisfação foi de 3,7. A média pessoal e institucional foi de 3,6 entre os não prounistas, já entre os que foram bolsistas as médias foram de 3,5 e 3,9 respectivamente. Destaca-se que a maior média geral está na satisfação social que tiveram durante a graduação. Tais dados parecem revelar a afinidade desses egressos com os cursos de licenciatura. Esses dados vão ao encontro dos dados apresentados na Tabela 3 , acerca dos aspectos que os levaram à escolha do curso, ou seja, afinidades, habilidades, desafios e interesses sociais. Não houve significância estatística entre os dois grupos.

Observa-se na Tabela 5 que 69,2\% (36) dos 52 egressos trabalham na área de formação, correspondendo esse valor a 44,2\% (23) dos que não tiveram bolsa e $25 \%$ (13) dos que tiveram. 


\begin{tabular}{|c|c|c|c|c|c|c|c|c|}
\hline \multirow{2}{*}{$\begin{array}{c}\text { SATISFAÇÃO } \\
\text { COM } \\
\text { TRABALHO } \\
\text { ATUAL }\end{array}$} & \multicolumn{2}{|c|}{$\begin{array}{c}\text { NÃO } \\
\text { TRABALHA }\end{array}$} & \multicolumn{3}{|c|}{ TRABALHA NA ÁREA } & \multicolumn{2}{|c|}{$\begin{array}{c}\text { NÃO TRABALHA } \\
\text { NA ÁREA }\end{array}$} & \multirow[b]{2}{*}{$\begin{array}{l}\text { TOTAL } \\
\text { Fr. (\%) }\end{array}$} \\
\hline & $\begin{array}{l}\text { Não } \\
\text { ProUni } \\
\text { Fr. (\%) }\end{array}$ & $\begin{array}{l}\text { ProUni } \\
\text { Fr. (\%) }\end{array}$ & $\begin{array}{c}\text { Não } \\
\text { ProUni } \\
\text { Fr. (\%) }\end{array}$ & $\begin{array}{l}\text { ProUni } \\
\text { Fr. (\%) }\end{array}$ & $\begin{array}{l}\text { Subtotal } \\
\text { Fr. (\%) }\end{array}$ & $\begin{array}{c}\text { Não } \\
\text { ProUni } \\
\text { Fr. (\%) }\end{array}$ & $\begin{array}{l}\text { ProUni } \\
\text { Fr. (\%) }\end{array}$ & \\
\hline $\begin{array}{l}\text { Totalmente } \\
\text { satisfeito }\end{array}$ & 0 & 0 & $6(26,2)$ & $4(30,8)$ & $10(27,8)$ & $2(14,3)$ & 0 & $12(23,1)$ \\
\hline $\begin{array}{l}\text { Parcialmente } \\
\text { satisfeito }\end{array}$ & 1 & 0 & $13(56,5)$ & $5(38,5)$ & $18(50)$ & $11(78,6)$ & $\mathbf{0}$ & $30(57,7)$ \\
\hline $\begin{array}{l}\text { Nem insatisfeito } \\
\text { nem satisfeito }\end{array}$ & 0 & 1 & $1(4,3)$ & $2(15,4)$ & $3(8,3)$ & $1(7,1)$ & 0 & $5(9,6)$ \\
\hline $\begin{array}{l}\text { Parcialmente } \\
\text { insatisfeito }\end{array}$ & 0 & 0 & $2(8,7)$ & $1(0,8)$ & $3(8,3)$ & 0 & 0 & $3(5,8)$ \\
\hline $\begin{array}{l}\text { Totalmente } \\
\text { insatisfeito }\end{array}$ & 0 & 0 & $1(4,3)$ & $1(0,8)$ & $2(5,6)$ & 0 & 0 & $2(3,8)$ \\
\hline TOTAL & $1(1,9)$ & $1(1,9)$ & $\begin{array}{c}23(63,9 \\
\text { e } 44,2)\end{array}$ & $\begin{array}{c}13(36,1 \\
\text { e } 25)\end{array}$ & $36(69,2)$ & $14(26,9)$ & $\mathbf{0}$ & $52(100)$ \\
\hline
\end{tabular}

FONTE: Banco de dados formado pelas respostas dos questionários.

Entre os não prounistas o percentual foi de 63,9\% (23) e entre os prounistas ficou em 36,1\% (13). Esse percentual de egressos atuando na área de formação vai ao encontro de estudos realizados por Felicetti, Cabrera e Morosini (2014) com egressos ProUni, não somente dos cursos de licenciatura, que apontaram que $65,8 \%$ dos respondentes trabalhavam na área de formação. Na Tabela 5, é possível identificar o percentual de satisfação com o trabalho atual e/ou o exercício da docência sendo este associado com o trabalhar ou não na área de formação. Apenas dois egressos não se encontravam trabalhando quando da pesquisa, um de cada grupo, correspondendo a $3,8 \%$ dos 52 respondentes. Destaca-se a opção parcialmente satisfeito com maior percentual, tanto para os que foram bolsistas ProUni como para os que não foram e que trabalham na área de formação, tendo os não prounistas o percentual de 56,5\% (13) e os que foram bolsistas 38,5\% (5). Somando tais percentuais obtém-se 50\% (18) dos que atuam na área com o grau parcialmente satisfeito com o trabalho atual. Entre os que não atuam na área, somente os que não foram bolsistas, a opção parcialmente satisfeito teve maior percentual, o qual foi de 78,6\% (11). Desse modo, o maior percentual em relação ao total de respondentes foi na opção parcialmente satisfeito com $57,7 \%$ (30). Com relação às opções que envolvem algum grau de insatisfação, ou seja, parcialmente ou totalmente insatisfeito, somando ambas perfez $9,6 \%$ em relação aos 52 egressos respondentes.

A opção, parcialmente satisfeito indicada com destaque na Tabela 5, pode ser explicada por diversos fatores, entre eles a desvalorização social da classe 
docente e os baixos salários (TANURI, 2000). Isso pode ser justificado pelo contexto atual da docência, no qual ao professorado, segundo Nóvoa (2009) é exigido além do seu ofício de professor, isto é, o professor é responsabilizado por questões sociais e muitas vezes tem que dar conta de responsabilidades que são inerentes aos pais. Aspectos como desvalorização docente, o baixo status dado à profissão, as baixas remunerações e a falta de apoio de gestores da educação contribuem para a insatisfação na profissão. Nessa direção, Aranha e Souza escrevem que "[...] é o baixo valor do diploma de professor, sobretudo na educação básica, tanto no mercado de bens econômicos (salário) quanto no mercado de bens simbólicos (prestígio)." (2013, p. 78) um contributivo à crise na profissão docente. Não houve significância estatística entre os grupos de egressos.

Por outro lado, a convicção da escolha certa pelo curso e/ou pela profissão é denotada ao se analisar as respostas da pergunta: Se você pudesse começar de novo, você faria o mesmo curso? Os dados, constantes na Tabela 6, indicam que a maioria dos egressos, em ambos os grupos, optariam definitivamente ou provavelmente pelo sim, o que resulta no percentual final de 71,2\% (37). Dados similares foram encontrados por Felicetti, Cabrera e Morosini (2014) em pesquisa com egressos ProUni que apontou $73,2 \%$ dos egressos respondendo que se pudessem começar novamente a universidade optariam definitiva ou provavelmente sim pela realização do mesmo curso.

TABELA 6 - SE PUDESSE COMEÇAR DE NOVO, FARIA O MESMO CURSO

\begin{tabular}{cccc}
\hline COMEÇAR DE NOVO & Não ProUni & ProUni & TOTAL \\
& Fr. (\%) & Fr. (\%) & Fr. (\%) \\
\hline Definitivamente sim & $11(28,9)$ & $\mathbf{5 ( 3 5 , 7 )}$ & $16(30,8)$ \\
Provavelmente sim & $15(39,5)$ & $6(42,9)$ & $21(40,4)$ \\
Sem opinião formada & $2(5,3)$ & 0 & $2(3,8)$ \\
Provavelmente não & $8(21,1)$ & $3(21,4)$ & $11(21,2)$ \\
Definitivamente não & $2(5,3)$ & 0 & $2(3,8)$ \\
\hline TOTAL & $38(100)$ & $14(100)$ & $52(100)$ \\
\hline
\end{tabular}

FONTE: Banco de dados formado pelas respostas dos questionários.

Tais dados reforçam os apresentados na Tabela 2, ou seja, a satisfação ou a realização no ambiente de trabalho está associada à congruência entre o tipo de personalidade e o ambiente (WALSH; HOLLAND, 1992; FELDMAN; NEWCOMB, 1969) evidenciando assim a congruência entre afinidades, habilidades e a função social delineada pelos respondentes com a área escolhida (VALLE, 2006). Para Tardif (2007, p. 23) isso representaria um professor de profissão, ou seja, "um sujeito que assume sua prática a partir dos significados que ele mesmo lhe dá [...].”. 
Quanto à realização de algum curso após a graduação, pode-se observar na Tabela 7 que o maior percentual em ambos os grupos 34,2\% (13) não ProUni e 42,9\% (6) ProUni refere-se à realização de cursos de especialização relacionado com a graduação, o que denota a relevância dada por esses profissionais à profissão, uma vez que estão realizando cursos a fim de melhorarem o fazer docente. Não houve significância estatística entre egressos ProUni e não ProUni.

TABELA 7 - REALIZAÇÃO DE ALGUM CURSO APÓS A GRADUAÇÃO

\begin{tabular}{|c|c|c|c|}
\hline CURSO APÓS A GRADUAÇÃO & $\begin{array}{c}\text { Não ProUni } \\
\text { Fr. (\%) }\end{array}$ & $\begin{array}{l}\text { ProUni } \\
\text { Fr. (\%) }\end{array}$ & $\begin{array}{l}\text { TOTAL } \\
\text { Fr. }(\%)\end{array}$ \\
\hline $\begin{array}{l}\text { Curso de Especialização não relacionado } \\
\text { com a formação }\end{array}$ & $3(7,9)$ & $2(14,3)$ & $5(9,6)$ \\
\hline $\begin{array}{c}\text { Curso de Especialização relacionado com } \\
\text { a graduação }\end{array}$ & $13(34,2)$ & $6(42,9)$ & $19(36,5)$ \\
\hline Curso de língua estrangeira & $3(7,9)$ & $2(14,3)$ & $5(9,6)$ \\
\hline Não & $10(26,3)$ & $3(21,4)$ & $13(25,0)$ \\
\hline Outra Graduação & $4(10,5)$ & $1(7,1)$ & $5(9,6)$ \\
\hline $\begin{array}{c}\text { Pós-graduação stricto sensu (mestrado, } \\
\text { doutorado) }\end{array}$ & $5(13,2)$ & 0 & $5(9,6)$ \\
\hline TOTAL & $38(100)$ & $14(100)$ & $52(100)$ \\
\hline
\end{tabular}

FONTE: Banco de dados formado pelas respostas dos questionários.

Nessa direção, Freire (1997) afirma que o professor necessita qualificar sua profissão para ter credibilidade em seu fazer pedagógico, pois segundo o autor, o professor ao estudar está esforçando-se para estar à altura de sua tarefa. "Isso significa dizer que há a necessidade de um contínuo estudo, o que torna o profissional cada vez mais qualificado em sua profissão, podendo contribuir com maior êxito na sua área de atuação" (FELICETTI, 2011b, p. 4).

\section{Conclusão}

O que leva as pessoas a optarem pelos cursos de licenciatura ao ingressarem na universidade? O quanto estão satisfeitos ou insatisfeitos com a formação conquistada? O quanto estão satisfeitos ou insatisfeitos com o exercício da docência?

Os resultados da pesquisa aqui apresentados indicam possíveis respostas às perguntas acima traçadas. Colocam-se como possíveis, pois o estudo em questão ocupou-se apenas de egressos de uma IES (Instituição de Educação 
Superior), o que não caracteriza dizer que as questões estão respondidas, mas pelo contrário, que novas investigações em um contexto maior são necessárias.

O universo de egressos dos cursos de licenciatura respondentes ao instrumento aqui proposto dá indicativos de que a escolha inicial do curso se deu por afinidades e habilidades; pela vontade de investir em novos desafios e por terem a percepção da relevância social da profissão em pauta. Tais opções de escolha para com as licenciaturas não apresentaram diferença entre ser ou não ser bolsista. Em ambos os grupos suas convicções iniciais de escolha do curso foram se estabelecendo no percurso deste, no vencer as dificuldades que se mostraram e que foram superadas, denotando talvez que a permanência até a integralização, está sim associada às afinidades, habilidades e convicções com respeito à profissão. Isso, independentemente de ser bolsista ou não, pois são no contínuo da formação docente que são fortalecidas as convicções pela profissão, necessitando de empenho, dedicação e persistência até a integralização do curso de todos que nele ingressam.

Se por um lado tem-se a escolha pelo magistério sendo inibida pela desvalorização social, pelo baixo retorno financeiro e pelas inúmeras atribuições à profissão designadas, quer seja quando do ingresso no mundo acadêmico ou quando do ingresso na docência, por outro lado, tem-se a escolha pela profissão. Essa escolha é caracterizada, neste estudo, pelas opções quando do ingresso em um curso de licenciatura e a congruência com as opções quando do exercício da docência. Isso é evidente quando os respondentes, sejam eles prounistas ou não, mostram em sua maioria, $71,2 \%$ que estão dispostos a realizarem o mesmo curso caso pudessem começar novamente.

Os resultados demonstram que os aspectos relacionados às características iniciais dos candidatos à docência contribuem para com a superação e/ou com o lidar no jogo das diferenças. Diante disso, para atender as demandas impostas à profissão exige-se muito mais que profissionais apenas graduados e preparados para atuarem em Matemática, Biologia ou qualquer área entre as licenciaturas, mas sim melhoradas e aprimoradas suas habilidades, afinidades e convicções acerca do que realmente vem a ser a docência. Pois nela somente permanecem os que de fato preparados estão a enfrentarem e superarem os desafios impostos diariamente pelo jogo das diferenças. Isso significa dizer que o querer ser professor está associado ao saber da responsabilidade social que compete à profissão, está associado ao gostar de ser professor, implica abraçar uma causa que muitas vezes parece perdida, é embrenhar-se num fazer sem fim e enfrentar desafios. É ser professor de profissão, aptidão e doação, pois somente assim se tem forças para continuar...

Os dados aqui apresentados, apontam caminhos para melhor compreender o porquê da escolha pela profissão professor, independentemente de ser bolsista 
ProUni ou não, pois ambos os grupos parecem ter os mesmos sentimentos em relação à profissão, dando sentido natural à escolha e parecendo representar saber por que investem energia em um ofício que muitas vezes parece não ter perspectivas futuras.

\section{REFERÊNCIAS}

ALMEIDA, J. S. de. Mulher e educação: a paixão pelo possível. São Paulo: UNESP, 1998.

ALVES, A. G. O desempenho acadêmico dos alunos do Programa Universidade para Todos. 2008. 71 f. Dissertação (Mestrado em Educação: Currículo) - Pontifícia Universidade Católica de São Paulo, São Paulo, 2008.

ARANHA, A. V. S.; SOUZA, J. V. A. de. As licenciaturas na atualidade: nova crise? Educar em Revista, Curitiba, Brasil: Editora UFPR, n. 50, p. 69-86, out./dez. 2013.

BOOTH, W. C.; COLOMB, G. C.; WILLIAMS, J. M. A arte da pesquisa. São Paulo: Martins Fontes, 2000.

BORCHERT, M. Career choice factors of high school students. Master of Science Degree with a Major in Career and Technical Education. University of Wisconsin-Stout, 2002. Disponível em: $<\mathrm{http}: / / \mathrm{www} 2 . u w s t o u t . e d u / c o n t e n t / l i b /$ thesis/2002/2002borchertm.pdf >. Acesso em: 15 out. 2014.

BÓS, A. J. G. EpiInfo sem mistérios: um manual prático. Porto Alegre: EDIPUCRS, 2004.

BRASIL. Lei no 13.005, de 25 de junho de 2014. Aprova o Plano Nacional de Educação - PNE e dá outras providências. Presidência da República. Brasília, DF: Diário Oficial da União. Disponível em:<http://www.planalto.gov.br/CCIVIL_03/_Ato2011-2014/2014/ Lei/L13005.htm>. Acesso em: 7 jul. 2014.

BRITO, M. R. F. de. Enade 2005: perfil, desempenho e razão da opção dos estudantes pelas licenciaturas. Avaliação: Revista da Avaliação Superior, Campinas, v. 12, n. 3, p. 401-443, 2007.

FELDMAN, K. A; NEWCOMB, T. M. The impact of college on students. San Francisco: Jossey-Bass, 1969.

FELICETTI, V. L. Comprometimento do estudante: um elo entre aprendizagem e inclusão social na qualidade da Educação superior. 2011. Tese (Doutorado) - Faculdade de Educação, PUCRS. Porto Alegre: 2011a.

FELICETTI, V. L. Teacher education: from education to teacher substance and practice. Research in Higher Education Journal, v. 13, p. 1-8, 2011b. Disponível em: <http://www. aabri.com/rhej.html>. Acesso em: 25 maio 2013. 
FELICETTI, V. L.; CABRERA, A. F.; MOROSINI, M. C. Aluno PROUNI: Impacto Na Instituição de Educação Superior e na Sociedade. Revista Iberoamericana de Educación Superior (RIES), n. 13, v. 2014, p. 21-39. Disponível em: $<$ http://ries.universia.net/index. php/ries/article/view/311/pdf_75>. Acesso em: 25 out. 2014.

FERNANDES, M. C. S. G. Escolha profissional e prática docente: o discurso de professores do ensino superior privado. In: REUNIÃO ANUAL DA ANPEd, 27., 2004, Caxambu. Anais... Caxambu: Associação Nacional de Pós-Graduação e Pesquisa em Educação, 2004.

FREIRE, P. A pedagogia da autonomia. Rio de Janeiro: Paz e Terra, 1997.

GRAMANI, M. C. N.; SCRICH, C. Influência do Desempenho Educacional na Escolha da Profissão. Cadernos de Pesquisa, v. 42 n. 147, p.868-883, set./dez. 2012. Disponível em: $<$ http://www.researchgate.net/publication/262778892_The_influence_of_educational_performance_on_the_choice_of_career>.Acesso em: 17 out. 2014.

LOCKE, E. A. The Nature and Causes of Job Satisfation. In: Dunnette, M. D., editors. Hondbook of Industrial and Organizational Psychology. Chicago: Rand McNally, 1976. p. 1297-1349.

NÓVOA, A. A solução pode estar no trabalho de pensar o trabalho. [Abril de 2004]. Portugal: Número Zero. Entrevista conduzida por João Rita.

NÓVOA, A. Professores: imagens do futuro presente. Lisboa: Educa, 2009.

RABELO, A. O. Professores homens nas séries iniciais: escolha profissional e mal-estar docente. Educação e Realidade, v. 35, p. 279-298, 2010. Disponível em: <http://seer. ufrgs.br/educacaoerealidade/article/viewFile/8198/9481>. Acesso em: 11 nov. 2017.

SAHLBERG, P. Finnish Lessons: What can the world learn from educational change in Finland? New York: Teachers College Press, 2011.

SECO, G. M. S. B. satisfação dos professores: algumas implicações práticas para os modelos de desenvolvimento profissional docente. Educação \& Cultura, n. 8, p.73-92, 2005.

SMART, J. C.; FELDMAN, K. A.; ETHINGTON, C. A. Academic Disciplines: Holland's theory and the study of college students and faculty. Nashville, Tennessee: Vanderbilt University Press, 2000.

SPLAVER, S. Your personality and your career. New York, NY: Julian Messner, 1977.

TANURI, L. M. História da formação de professores. Revista Brasileira de Educação, v. 14, p. 61-88, maio/jun./jul./ago. 2000.

TARDIF, M. Saberes docentes e formação profissional. Petrópolis/RJ: Vozes, 2007.

VALLE, I. R. Carreira do magistério: uma escolha profissional deliberada? Revista Brasileira de Estudos Pedagógicos, Brasília, v. 87, n. 216, p. 178-187, maio/ago. 2006. 
WALSH, W. B.; HOLLAND, J. L. A theory of personality types and work environments. In: Bruce Walsh, W.; Craik, K. H.; Price, R. H. Person-environment psychology: Models and perspectives. Hillsdade, N. J.: Lawrence Erlbaum Associates, 1992, p.35-69.

Texto recebido em 11 de fevereiro de 2017. Texto aprovado em 31 de outubro de 2017. 